\title{
Fibrinolytic therapy in meningitis and ventriculitis
}

\author{
G. T. STEWART \\ From Queen Mary's Hospital for Children, Carshalton
}

The deposition of fibrin in the meninges and ventricles of the central nervous system is a natural accompaniment of any form of infection in the cerebrospinal cavities. It occurs most strikingly in severe pyogenic infections such as pneumococcal meningitis, but in these infections nowadays prompt chemotherapy usually ensures the rapid resolution of the infection together with reabsorption of the fibrin, often within a few days of the onset of the disease. In certain infections, however, fibrin is less rapidly deposited and, although sometimes localized, is slow to absorb (Fig. 1). This state of affairs occurs classically in untreated meningitis and, as Dr. Lorber has shown, in tuberculous meningitis; and also in secondary meningitis due to organisms such as Proteus and Ps. pyocyanea which are relatively insusceptible to antibiotics. Patients with congenital deformity of the central nervous system, such as meningomyelocele, are especially prone to infection with these organisms, which may also cause serious

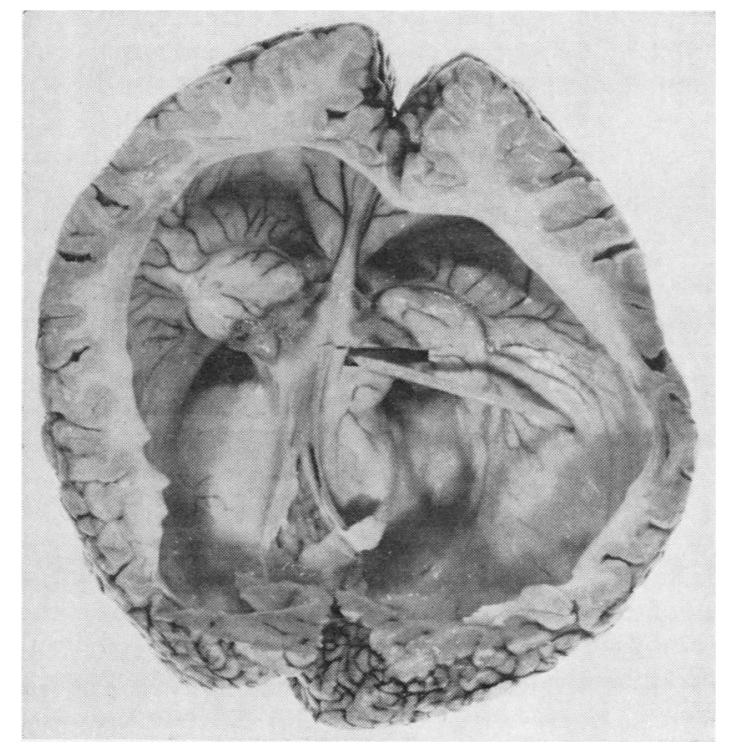

FIG. 1. Post-meningitic hydrocephalus with fibrinous deposition burying the choroid plexus in the right ventricle. difficulty if they gain access to the tissues directly or via the blood stream during neurosurgery. In general terms, absorption of the fibrin in inflammatory exudates around the brain and spinal cord is incomplete when there is delay in treating the infection, inadequate or inappropriate chemotherapy, infection by certain organisms (Proteus, Ps. pyocyanea, staphylococci) which may be resistant to prophylaxis as well as to therapy, obstruction to the flow of cerebrospinal fluid, increased protein in the cerebrospinal fluid, anatomical abnormality of the brain or cord, or a complex neurosurgical situation.

At Queen Mary's Hospital for Children about 150 cases of primary or secondary meningitis have been treated in the past three years. About 30 of these cases fell into one or more of the categories defined above, and they were studied in some detail with regard to the reasons for failure of fibrinolysis. Thirteen were selected for a trial of fibrinolytic therapy.

The treated patients comprise eight with meningomyelocele, two of whom developed meningitis soon after admission; six of them developed meningitis after surgical excision of the meningomyelocele. There was also one patient with acrocephaly developing meningitis after surgical repair of a hernia of the brain; two patients with hydrocephalus in whom Spitz-Holter valves became infected; and two patients with pyogenic meningitis in whom subarachnoid adhesions blocking the flow of cerebrospinal fluid developed in the course of normal treatment.

FIBRINOLYTIC MECHANISM IN THE CEREBROSPINAL FLUID

In normal cerebrospinal fluid with a protein content of only $20 \mathrm{mg} . \%$ or thereabouts, plasminogen is barely detectable. In acute pyogenic inflammation the protein content rises sharply, often to levels of $300 \mathrm{mg} . \%$ or more within a day or two. In chronic inflammation of any kind the protein level may rise much higher to as much as $3 \mathrm{~g} . \%$. Under these circumstances plasminogen increases sharply (Fig. 2) more or less in proportion to the rise in protein. 


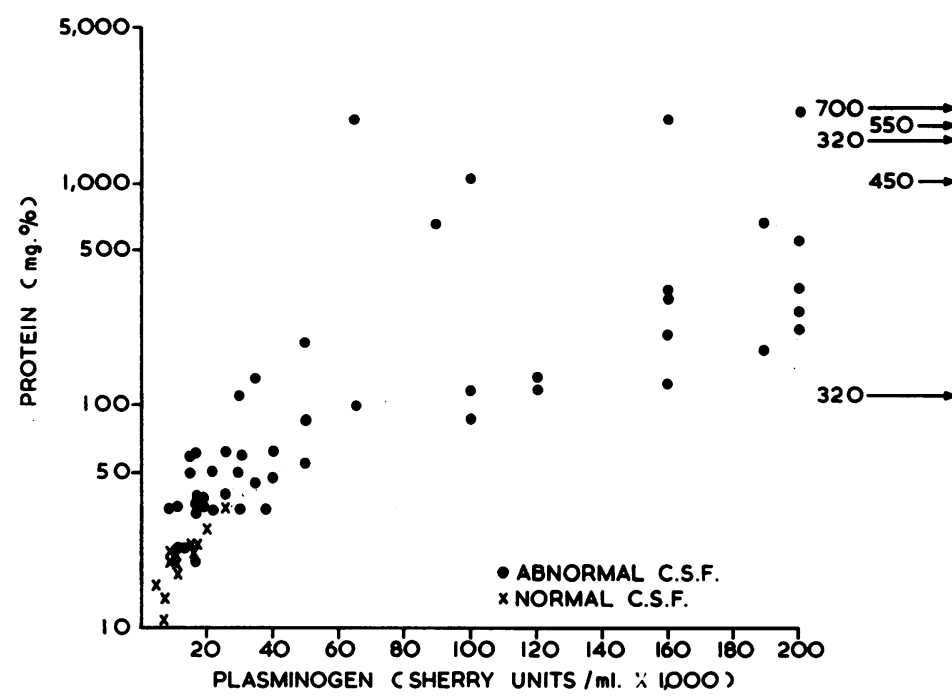

FIG. 2. Relationship between protein level and plasminogen in cerebrospinal fluid.

Free plasmin may be present, as can be shown by the fact that clots formed with cerebrospinal fluid as a component undergo slow spontaneous lysis, but it is difficult to measure the plasmin content and impossible to calculate the amount which is adsorbed to the fibrin. Plasminogen is of course readily activated by streptokinase and considerably shortens the lysis time of clots formed in cerebrospinal fluid. This process is neutralized by $\epsilon$-amino-caproic acid, (E.A.C.A.), showing that it depends upon conversion of the plasminogen to plasmin. If we assume that the Sherry hypothesis is correct, the best estimate of fibrinolytic activity could be the utilization of plasminogen rather than the demonstration of free

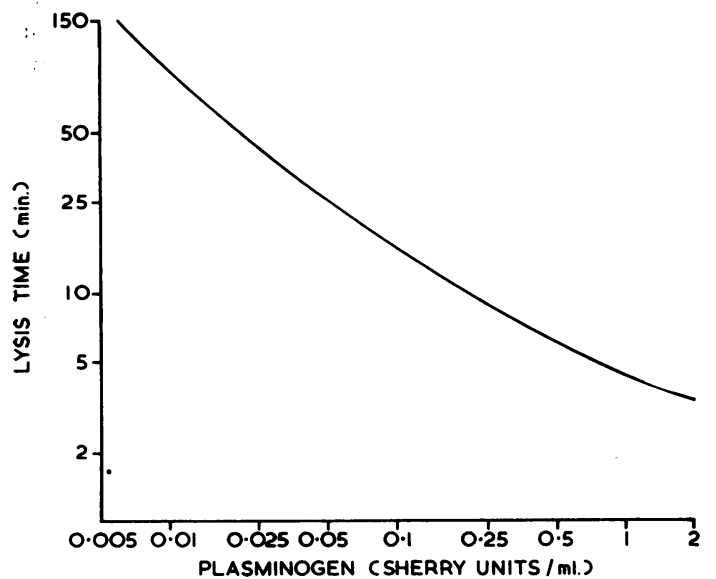

FIG. 3. Relationship between plasminogen concentration and lysis time in a standardized system. plasmin, provided that the system under study can be shown to produce digestion of fibrin. Dr. Newman, working in the laboratory here, has devised a technique based upon this principle. In this techniqueo bovine fibrinogen is clotted by the addition of thrombin, and cerebrospinal fluid is added as ao source of plasminogen. The addition of streptokinase then causes lysis of the clot, the lysis time being inversely related to the amount of plasminogen present $\overrightarrow{\vec{\sigma}}$ (Fig. 3). We have used this technique to investigate 3 these cases and to control therapy by estimating the plasminogen content and its utilization in the cerebrospinal fluid when activators are injected. The results obtained are comparable to those of the caseinolytic method, but the technique appears to be more sensitive in that it can detect with accuracyo small quantities of plasminogen.

Apart from the observations on clinical improvement or otherwise, we have tried to assess the effects? of giving activators by three other criteria: 1 The consumption of plasminogen, as detailed above 2 change in total protein content; 3 restoration of the flow of cerebrospinal fluid using, in some cases $N$ antibiotics as markers.

\section{FIBRINOLYTIC THERAPY}

This was given to 13 selected cases as an adjunct ore sequel to chemotherapy. Biochemical control by the methods described was exercised throughout therapy and is indeed essential at the present stage in all such investigations. We also attempted to assess toxicity by close observation during and aftero injections, by looking for changes in the cerebro spinal fluid, and by taking electro-encephalographio 
recordings before, during, and after the administration of the activators.

\section{TECHNIQUE OF THERAPY}

Activators used were urokinase (Leo) and streptokinase (Kabi). They were given intraventricularly, intrathecally, or subdurally according to the site of the fibrinous lesion, and some children received them intravenously as well. Intraventricular therapy is easy when the ventricle is dilated, but requires great care when there is no dilatation or no hydrocephalus. The activator was administered in water, sometimes with protamine sulphate added. The usual dosage was 5,000 to 10,000 units intraventricularly or intrathecally daily or on alternate days.

\section{RESULTS OF THERAPY}

Of the 13 children treated (Table I), two showed permanent improvement and five temporary improvement. The remaining six children were un-

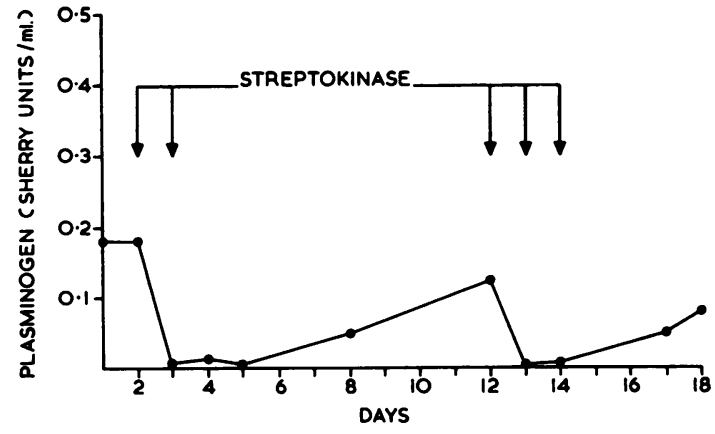

FIG. 4. Plasminogen levels in cerebrospinal fluid of a patient treated with two courses of intraventricular streptokinase.

affected by therapy and five succumbed rapidly to progressive hydrocephalus. Administration of either activator produced a fall in plasminogen which was uniform in all except one case. It is obvious that this fall was directly related to the administration of the

TABLE I

RESULTS OF FIBRINOLYTIC THERAPY AFTER INFECTIONS OF CENTRAL NERVOUS SYSTEM

\begin{tabular}{|c|c|c|c|c|c|c|c|c|}
\hline \multirow[t]{2}{*}{ Description } & \multirow[t]{2}{*}{ Case } & \multicolumn{2}{|c|}{ Treatment (days) } & \multicolumn{2}{|c|}{$\begin{array}{l}\text { Cerebrospinal } \\
\text { Fluid Protein } \\
\text { (mg. \%) }\end{array}$} & \multicolumn{3}{|c|}{ Clinical Improvement } \\
\hline & & Urokinase & Streptokinase & Before & After & Permanent & Temporary & None \\
\hline $\begin{array}{l}\text { Meningitis after repair of } \\
\text { meningomyelocele }\end{array}$ & $\begin{array}{l}\text { M.R. } \\
\text { C.O. } \\
\text { A.T. } \\
\text { S.M. } \\
\text { L.M. } \\
\text { K.B. }\end{array}$ & $\begin{array}{r}13 \\
48 \\
10 \\
3\end{array}$ & $\begin{array}{l}4 \\
2\end{array}$ & $\begin{array}{r}550 \\
1,200 \\
2,800 \\
300 \\
1,100 \\
900\end{array}$ & $\begin{array}{r}250 \\
200 \\
2,300 \\
300 \\
1,100 \\
2,400\end{array}$ & & D & 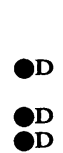 \\
\hline Meningomyelocele with & K.B. & 2 & & 700 & 1,900 & & & \\
\hline meningitis & K.F. & & 5 & 2,200 & 2,600 & & & \\
\hline $\begin{array}{l}\text { Meningitis with subarachnoid } \\
\text { block }\end{array}$ & $\begin{array}{l}\text { G.D. } \\
\text { U.U. }\end{array}$ & $\begin{array}{l}5 \\
4\end{array}$ & & $\begin{array}{l}350 \\
550\end{array}$ & $\begin{array}{l}950 \\
100\end{array}$ & & & \\
\hline Infection of Spitz-Holter valve & $\begin{array}{l}\text { J.H. } \\
\text { J.C. }\end{array}$ & 22 & 6 & $\begin{array}{l}200 \\
750\end{array}$ & $\begin{array}{r}200 \\
1,600\end{array}$ & & & \\
\hline $\begin{array}{l}\text { Acrocephalic hernia with } \\
\text { meningitis }\end{array}$ & E.M. & 25 & & 300 & 400 & & & D \\
\hline Totals & 13 & 9 & 4 & & & 2 & 5 & 6 \\
\hline
\end{tabular}

TABLE II

RESULTS OF FIBRINOLYTIC THERAPY AFTER INFECTIONS OF CENTRAL NERVOUS SYSTEM

\begin{tabular}{|c|c|c|c|c|c|c|c|c|}
\hline \multirow[t]{2}{*}{ Description } & \multirow{2}{*}{$\begin{array}{l}\text { No. of } \\
\text { Cases }\end{array}$} & \multirow[t]{2}{*}{ Organism } & & \multicolumn{2}{|l|}{ Treated } & \multicolumn{3}{|c|}{ Clinical Improvement } \\
\hline & & & & Urokinase & Streptokinase & Permanent & Temporary & None \\
\hline $\begin{array}{l}\text { Meningitis after repair of } \\
\text { meningomyelocele }\end{array}$ & 6 & $\begin{array}{l}\text { Pyocyanea } \\
\text { Proteus } \\
\text { Staph. }\end{array}$ & $\begin{array}{l}4 \\
1 \\
1\end{array}$ & 4 & 2 & 1 & 2 & 3 \\
\hline $\begin{array}{l}\text { Meningomyelocele with } \\
\text { meningitis }\end{array}$ & 2 & $\begin{array}{l}\text { Pyocyanea } \\
\text { Proteus }\end{array}$ & $\begin{array}{l}1 \\
1\end{array}$ & 1 & 1 & & & 2 \\
\hline $\begin{array}{l}\text { Meningitis with subarachnoid } \\
\text { block }\end{array}$ & 2 & $\begin{array}{l}\text { Staph. } \\
\text { Meningo. }\end{array}$ & $\begin{array}{l}1 \\
1\end{array}$ & 2 & & 1 & 1 & \\
\hline Infection of Spitz-Holter valve & 2 & $\begin{array}{l}\text { Staph. } \\
\text { Proteus }\end{array}$ & $\begin{array}{l}1 \\
1\end{array}$ & 1 & 1 & & 2 & \\
\hline $\begin{array}{l}\text { Acrocephalic hernia with } \\
\text { meningitis }\end{array}$ & 1 & Pyocyanea & 1 & 1 & & & & 1 \\
\hline Totals & 13 & & & 9 & 4 & 2 & 5 & 6 \\
\hline
\end{tabular}



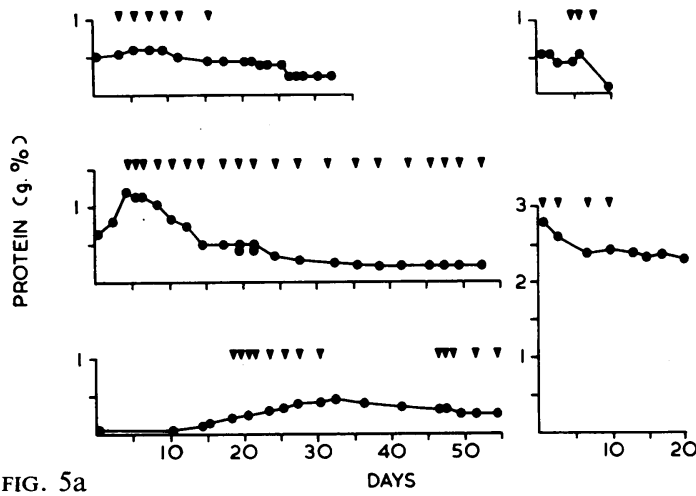

FIG. $5 \mathrm{a}$
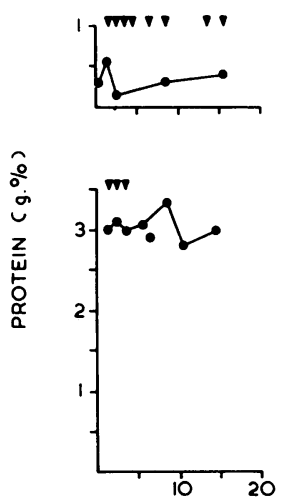

FIG. $5 b$
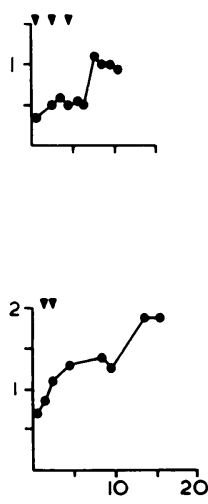

DAYS
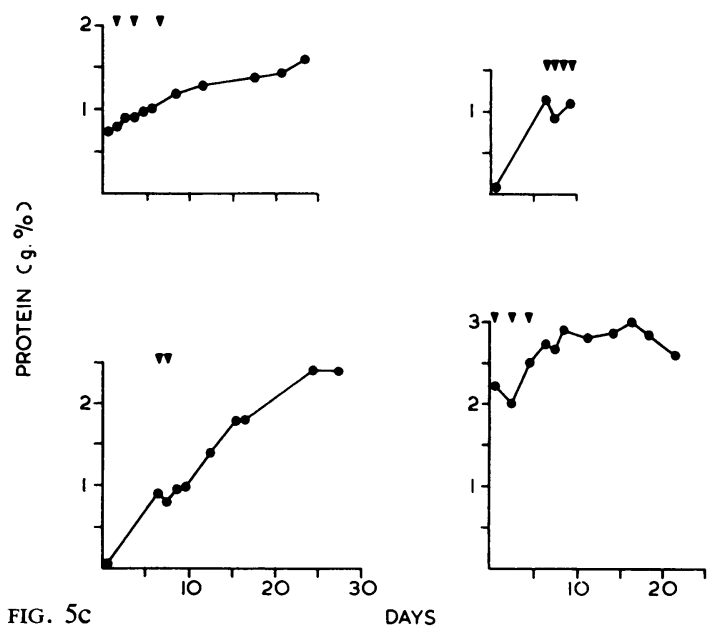

FIG. 5. (a) Protein levels in cerebrospinal fluid of patients treated with intraventricular urokinase (1); (b) Protein levels in cerebrospinal fluid of patients treated with intraventricular urokinase (2); (c) Protein levels in cerebrospinal fluid of patients treated with intraventricular streptokinase. activator, for plasminogen reappeared when the activator was withdrawn (Fig. 4) and diminished again when it was restarted. Three cases showed a consistent fall in cerebrospinal fluid protein level, while three others showed a temporary fall (Fig. 5). Inhibitor substances were abundant in the sera of these children, but none were detected in the cerebrospinal fluid. Both activators were well tolerated; there were no clinical signs of irritation के of the central nervous system, nor did the cerebro- $\overrightarrow{0}$ spinal fluid show pleocytosis, eosinophilia, or a sharp rise in protein content such as occur with $\vec{\omega}$ other irritant injections. Electro-encephalographic recordings showed at most some temporary? asymmetry. The best results, clinically and bio- $\vec{v}$ chemically, were obtained in children treated with $\omega$ urokinase (Table II) but the series was too small to of permit close comparison of the two activators. Our purpose at this stage was to explore the possibilities of fibrinolytic therapy in general terms rather than to compare these substances.

Follow-up of these 13 cases which have been treated during the past three years shows that four are now alive. One of these four children is very well indeed and when you consider her original state, with a large meningomyelocele, incipient hydrocephalus, and pyocyanea meningitis, her present development physically and intellectually is highly satisfactory (Fig. 6). One of the others is also very well, though in this child the original lesion

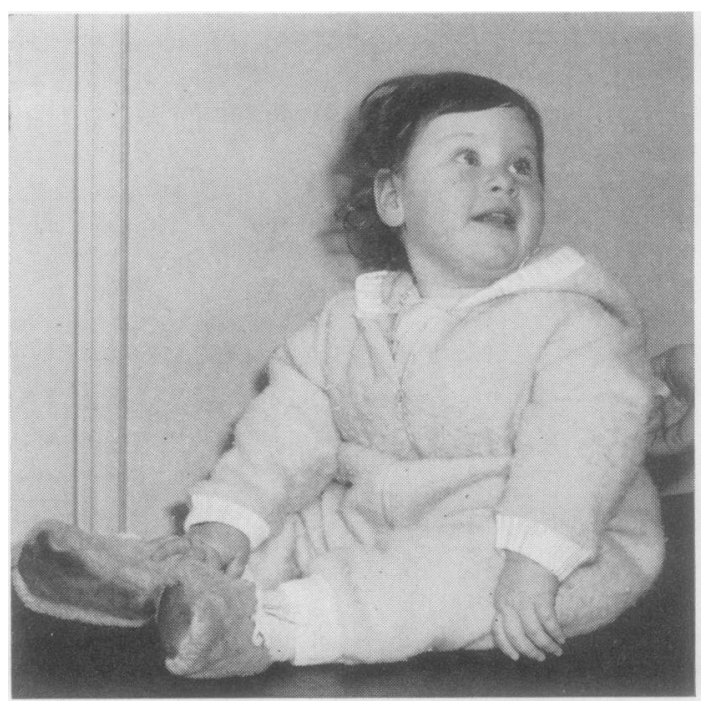

FIG. 6. C.O. aged 1 year; photograph taken 10 months after cessation of fibrinolytic and antibiotic therapy for secondary meningitis due to Ps. pyocyanea, after excision of meningocele on second day of life. 
(meningococcal meningitis) was uncomplicated except by the subarachnoid block which was rapidly alleviated. Another patient, also with subarachnoid block, made a reasonably good recovery but the protein level in the cerebrospinal fluid is still high and prognosis must be guarded. The fourth child has a moderate degree of hydrocephalus. The best results undoubtedly occurred in those children who received activator at the earliest possible stage, sometimes with the first dose of antibiotic.

Four of the children died from other causes, such as bronchopneumonia, and the final effects of treatment are difficult to assess. The remaining five died rapidly of acute hydrocephalus and in these the treatment failed.

In the assessment of these results it should be remembered that in all except two of the children there were major congenital abnormalities in the central nervous system. Even if meningitis had not occurred, prognosis would have been poor for this reason alone. Viewed in this way, the results are in some respects encouraging. It may therefore be justifiable to conclude from this investigation that plasminogen is present in the cerebrospinal fluid in inflammatory states and can be activated by streptokinase and urokinase to form plasmin. The new and purified preparations of streptokinase and urokinase are well tolerated in the central nervous system. Given locally in the manner described, these activators may promote lysis of fresh fibrin and given early in severe infections, they may also prevent deposition of fibrin.

DR. JAMES commented on the thromboplastic activity of the cerebrospinal fluid. He pointed out that thromboplastin for estimating the ordinary prothrombin time was obtained from human brain. For this reason he felt that trauma to the brain with a catheter or needle would be a very good source of thromboplastic material and hence of fibrin clot. This might be the explanation of fibrin formation in the subarachnoid space in some of these patients.

PROFESSOR GILLINGHAM in summing up said that during the past 15 years he had been profoundly impressed by the fact that there are reactors and non-reactors. He felt that further study must be more detailed and should involve team work between the surgeon, biochemist, and pharmacologist. He thought that it would be important to determine the nature of the deposits which form at the end of the tubes of various shunts used in the treatment of hydrocephalus and of the impervious membrane which sometimes lines the serous cavities following the various shunts of cerebrospinal fluid. Although it cannot obviously be proved that protein plays a part in the production of fibrinous clots within the tubes or in the formation of the impervious membranes in the serous cavities which follow the various shunt procedures, it might be that there is an excess of a certain protein, such as fibrinogen. A few years ago, using electrophoretic methods, excessive fibrinogen had been found in the cerebrospinal fluid of some infants with communicating hydrocephalus. 